\title{
KUALITAS MIKROBIOLOGI SUSU KAMBING SEGAR DARI SEBUAH PETERNAKAN KAMBING PERAH SKALA KECIL DI DESA CIMALAKA, SUMEDANG
}

\author{
Gita Pidya Pradini', Nisa Fauziah' ${ }^{1}$, Rini Widyastuti ${ }^{2}{ }^{3}$, dan \\ Mas Rizky Anggun Adipurna Syamsunarno ${ }^{1}$ \\ ${ }^{1}$ Departemen Ilmu Kedokteran Dasar, Fakultas Kedokteran Universitas Padjadjaran. \\ ${ }^{2}$ Laboratorium Reproduksi dan Inseminasi Buatan, Departemen Produksi Ternak, Fakultas Peternakan. \\ Universitas Padjadjaran. \\ ${ }^{3}$ Program Studi Kedokteran Hewan, Fakultas Kedokteran Universitas Padjadjaran. \\ E-mail: gita.widya.pradini@unpad.ac.id
}

\begin{abstract}
ABSTRAK. Susu kambing merupakan salah satu sumber susu yang dipercaya memiliki banyak manfaat oleh masyarakat. Dalam praktik penjualannya, sebagian besar peternak skala kecil di Indonesia tidak melakukan proses sterilisasi atau pasteurisasi susu. Adanya kepercayaan masyarakat bahwa susu kambing mentah lebih berkhasiat menjadi perhatian akan risiko penularan mikroba patogen. Kegiatan ini bertujuan untuk mengetahui kualitas mikrobiologi susu kambing mentah dari sebuah peternakan kambing perah di Desa Cimalaka serta memberikan penyuluhan dan survey kepada masyarakat dan peternak kambing perah di desa tersebut. Dari salah satu peternakan, didapatkan 6 ekor kambing perah peranakan Etawah. Setiap kambing dilakukan pemerahan susu sebanyak $\pm 10 \mathrm{ml}$. Sampel susu kemudian dinilai kualitas mikrobiologi berdasarkan hasil perhitungan angka lempeng total (ALT) serta identifikasi bakteri Staphylococcus koagulase positif dan bakteri koliform. Batas maksimal jumlah bakteri dalam ALT ditentukan berdasarkan Standar Nasional Indonesia (SNI) 1788:2009. Dalam kegiatan penyuluhan terdapat 20 responden yang mengikuti survey, 14 di antaranya merupakan peternak kambing perah. Hasil pemeriksaan mikrobiologi menunjukkan seluruh sampel susu memenuhi kriteria SNI berdasarkan ALT. Pertumbuhan bakteri koliform tidak ditemukan pada seluruh sampel. Ditemukan cemaran Staphylococcus koagulase positif pada dua sampel dan cemaran bakteri enterik non-koliform pada dua sampel lainnya yang berpotensi sebagai patogen. Hasil survey menunjukkan sebagian besar responden terbiasa mengonsumsi susu mentah, dan praktik peternak dalam menjaga sanitasi kandang dan higienitas susu masih belum baik Temuan ini menunjukkan pentingnya peningkatan pengetahuan dan praktik peternak dalam manajemen hewan ternak dan susu segar. Praktik meminum susu kambing mentah perlu dihindari karena berisiko tinggi terkontaminasi mikroba patogen.
\end{abstract}

Kata kunci: sanitasi; higiene; susu kambing segar; kualitas mikrobiologi

ABSTRACT. Goat's milk is an alternative source of milk which believed to have many benefits for human health. Current practice on fresh goat's milk selling showed most of local small scale farmer sold fresh goat's milk without prior pasteurization or sterilization process. This practice have raised concern about consumer's risk on transmission of pathogenic microbes since many people believed consuming raw goat milk is more beneficial. This study aim to analyze microbiological quality of raw goat milk from a small scale dairy farm in Cimalaka Village, perform counselling and survey to milk farmer and community village. Total 6 milk samples (each volume $\pm 10 \mathrm{ml}$ ) from 6 lactating goats (Etawa crossbreed) are collected. Microbiological quality were assessed based on Total Plate Count (TPC), and screened for coagulase positive Staphylococci and coliform contamination. The TPC value for raw goat milk was evaluate based on Indonesian national standard for raw milk (SNI 1788:2009). Result showed all samples meet SNI criteria for TPC value and no coliform contamination were found. Nevertheless, two samples contaminated with coagulase positive Staphylococci and two other had non-coliform enteric bacteria contamination. Both bacteria are consider pathogenic. Result from survey showed most of respondents were used to consume raw milk and the farmer's practices on maintain milk hygiene and sanitation of goat's pen were lacking. This finding suggest a need to improve dairy farmer knowledge and practice on cattle management and raw milk handling. Moreover, practice on drinking raw milk should be discouraged as it pose risk for pathogenic microbial contamination.

Keywords: Sanitation; hygiene; fresh goat milk; microbiology quality

\section{PENDAHULUAN}

Susu kambing merupakan salah satu alternatif sumber susu bagi masyarakat Indonesia. Susu kambing diketahui memiliki beberapa kelebihan dibandingkan susu sapi yaitu memiliki sifat mudah dicerna dan relatif tidak memicu alergi dibandingkan dengan susu sapi (Haenlein 2004). Saat ini konsumsi susu kambing segar mulai banyak diminati oleh masyarakat. Akan tetapi, sebagian besar peternakan kambing perah di Indonesia masih dikelola secara sederhana dalam skala kecil (Astuti, 2012). Dalam praktik penjualan susu kambing segar oleh peternak tradisional, seringkali susu kambing tidak diolah melalui proses pasteurisasi atau teknik sterilisasi lainnya. Susu kambing segar hasil perahan peternak langsung dikemas ke dalam kemasan plastik dan umumnya langsung dijual kepada masyarakat atau dibekukan (Nurliyani, 2015). Konsumen susu kambing di Indonesia pun masih banyak memilih untuk mengonsumsi susu kambing segar yang belum dilakukan proses pemasakan terlebih dahulu 
(Nurliyani, 2015; Taufik, 2011). Hal ini terjadi karena adanya kepercayaan di tengah masyarakat bahwa susu kambing mentah lebih berkhasiat untuk meningkatkan kesehatan serta memiliki fungsi sebagai obat untuk menyembuhkan penyakit tertentu (Taufik, 2011). Akan tetapi, seperti halnya susu segar lainnya, susu kambing dapat menjadi sumber penularan berbagai bakteri patogen seperti Staphylococcus aureus, Listeria monocytogenes, Campylobacter spp., dan bakteri koliform (Suguna, 2012). Hingga saat ini susu kambing segar masih kurang mendapatkan perhatian dari pemerintah atau lembaga terkait lainnya dalam hal kontrol kualitas, keamanan dan kebersihan produk susu (Nurliyani, 2015; Taufik, 2011).

Desa Cimalaka, Kabupaten Sumedang merupakan salah satu desa binaan Universitas Padjadjaran yang memiliki salah satu keunggulan dalam peternakan kambing perah. Berdasarkan wawancara yang dilakukan oleh tim Pengabdian Kepada Masyarakat (PKM) Fakultas Peternakan dan Fakultas Kedokteran Universitas Padjadjaran, pengetahuan peternak mengenai aspek cemaran mikroba dalam proses pemerahan susu kambing segar masih minim. Selain itu, masih ada sebagian masyarakat yang menyukai konsumsi susu kambing segar tanpa dimasak atau dipanaskan. Berdasarkan hasil pengamatan tim tersebut, maka dilakukan kegiatan penyuluhan mengenai cara pemerahan susu kambing yang baik untuk meminimalkan kontaminasi mikroba serta pemaparan mengenai pentingnya proses pemasakan susu sebelum dikonsumsi. Bakteri Staphylococcus aureus (Staphylococcus koagulase positif) dan bakteri koliform termasuk dalam indikator cemaran mikroba suatu bahan pangan, termasuk susu segar. Untuk mengetahui potensi cemaran mikroba pada susu kambing segar, tim PKM melakukan analisis kualitas mikrobiologi susu kambing segar yang diperoleh dari sebuah peternakan kambing skala kecil di Desa Cimalaka Kabupaten Sumedang. Indikator mikrobiologi yang digunakan adalah jumlah angka lempeng total, pertumbuhan bakteri Staphylococcus koagulase positif dan pertumbuhan bakteri koliform .

\section{METODE}

Kegiatan penyuluhan dilakukan dengan metode ceramah dan diskusi berupa tanya-jawab antara narasumber dan masyarakat yang hadir. Sasaran utama peserta penyuluhan adalah masyarakat dan peternak kambing perah di Desa Cimalaka. Kegiatan penyuluhan dilaksanakan di Balai Pertemuan Kelompok Peternak Kambing Peranakan Etawa Simpay Tampomas di Desa Cimalaka, Sumedang.

Kegiatan penyuluhan diawali dengan pengisian kuesioner yang berisi pertanyaan mengenai kebiasaan peternak ketika memerah susu kambing dan kebiasaan konsumsi susu kambing mentah pada seluruh peserta yang hadir. Setelah pengisian kuesioner selesai, dilakukan kegiatan ceramah dan diskusi mengenai teknik pemerahan yang baik untuk mencegah kontaminasi bakteri.

\section{Pengambilan sampel}

Enam sampel susu segar dari enam ekor kambing peranakan Etawa diambil dari sebuah peternakan skala kecil di desa Cimalaka, Sumedang. Pengambilan sampel dilakukan mengikuti jadwal pemerahan susu kambing (sekitar pukul 16.00 WIB) dan mengikuti prosedur rutin yang dilakukan pemerah. (Gambar 1) Sebelum dilakukan pemerahan, ambing dibersihkan dengan menggunakan air hangat yang dicampur dengan cairan antiseptik yang mendung iodium (tanpa takaran khusus), pemerah juga membilas kedua tangannya dengan cairan tersebut sebelum memerah susu. Sampel susu diambil dari setiap kambing sebanyak $\pm 10 \mathrm{ml}$ dan langsung ditampung dalam wadah steril. Sampel kemudian disimpan dalam kondisi dingin $\left( \pm 4^{\circ} \mathrm{C}\right)$ dan segera dibawa ke laboratorium untuk dilakukan pemeriksaan dalam waktu $<6$ jam.

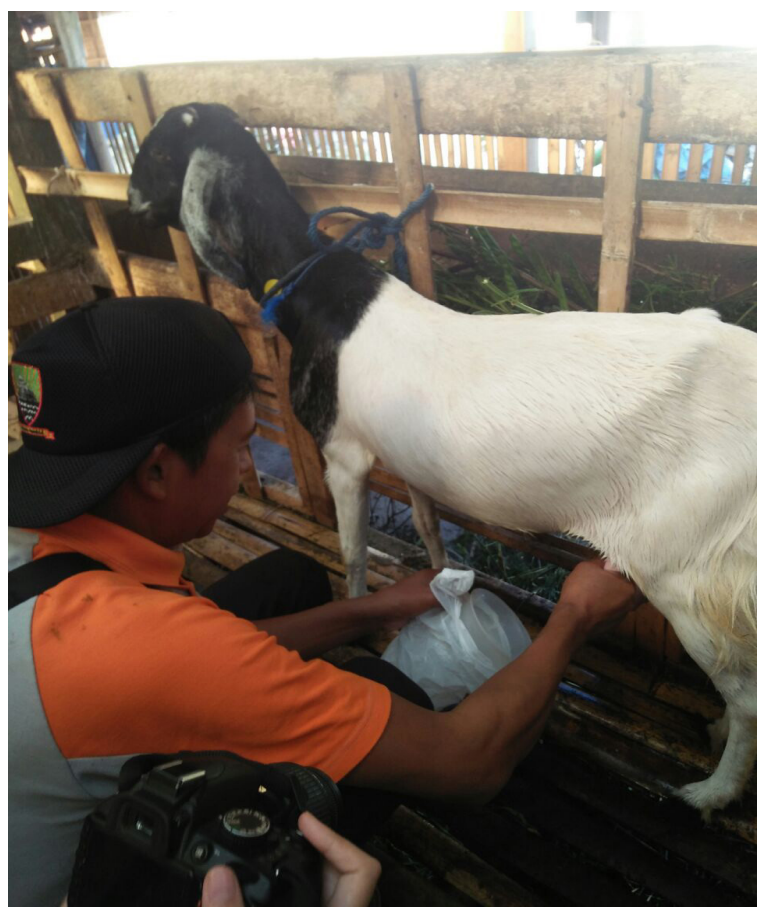

Gambar 1. Proses pemerahan susu kambing oleh peternak dengan menggunakan tangan

\section{Analisis Mikrobiologi}

Perhitungan Angka Lempeng Total (ALT)

Sebanyak $1 \mathrm{ml}$ sampel susu diencerkan dengan $\mathrm{NaCl}$ 0,9\% steril sebanyak 9ml. Kemudian dilakukan dilusi serial hingga pengenceran $10^{-4}$, sebanyak $1 \mathrm{ml}$ dari setiap tingkatan pengenceran diinokulasi dalam agar triptic soya untuk dihitung angka lempeng total pertumbuhan bakteri. Standar perhitungan angka 
lempeng total dibuat berdasarkan SNI 7388:2009 tentang batasan cemaran mikroba dalam pangan untuk kategori susu segar untuk langsung dikonsumsi yaitu maksimal $5 \times 10^{4} \mathrm{koloni} / \mathrm{ml}$.

\section{Identifikasi Bakteri Staphylococcus Koagulase Positif}

Sebanyak $1 \mathrm{ml}$ sampel susu diinokulasi pada agar darah. Sifat pertumbuhan Staphylococcus koagulase positif dinilai berdasarkan pertumbuhan koloni berwarna putih atau kekuningan dengan hasil pewarnaan gram positif bentuk kokus, uji katalase positif dan uji koagulase positif (Kateete, 2010).

\section{Identifikasi Bakteri Koliform}

Sebanyak $1 \mathrm{ml}$ sampel susu diinokulasi pada agar MacConkey. Bakteri koliform diidentifikasi berdasarkan pertumbuhan pada agar MacConkey dengan sifat fermentasi laktosa positif (perubahan warna agar menjadi kemerahan) dan sifat pewarnaan gram negatif bentuk batang.

\section{HASIL DAN PEMBAHASAN}

\section{Kegiatan Penyuluhan}

Kegiatan penyuluhan dihadiri oleh 30 orang masyarakat dan peternak kambing perah di Desa Cimalaka, Kabupaten Sumedang. Dari 30 peserta penyuluhan, terdapat 20 peserta yang bersedia mengisi kuesioner seputar perilaku dalam konsumsi susu mentah (Gambar 2) dan 14 orang diantaranya merupakan peternak kambing perah. Peternak kambing perah kemudian mengisi kuesioner lanjutan mengenai perilaku dalam memerah susu dan menangani susu, serta kebiasaan pembersihan kandang (Tabel 1).

\section{Konsumsi susu kambing mentah}

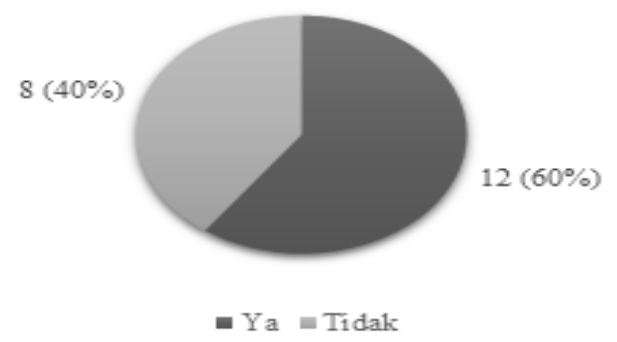

Gambar 2. Persentase peserta penyuluhan yang biasa mengonsumsi susu kambing mentah. Total responden: 20

Dari hasil pengisian kuesioner mengenai kebiasaan konsumsi susu kambing mentah, dapat disimpulkan bahwa sebagian besar (60\%) responden terbiasa mengonsumsi susu kambing mentah. Kebiasaan ini berisiko untuk terjadinya penularan mikroba patogen dari susu mentah yang dikonsumsi.
Sehingga perlu adanya tindak lanjut berupa sosialisasi atau penyuluhan mengenai risiko penyakit yang dapat ditimbulkan akibat konsumsi susu mentah yang tercemar mikroba patogen.

Tabel 2. Perilaku peternak dalam memerah dan menangani susu

\begin{tabular}{|c|c|c|c|c|}
\hline \multirow{3}{*}{\begin{tabular}{l}
\multicolumn{1}{c}{ Aspek Perilaku } \\
Membersihkan ambing \\
hewan sebelum memerah \\
susu
\end{tabular}} & & $\mathrm{n}$ & \multicolumn{2}{|l|}{$\%$} \\
\hline & Ya & 14 & \multicolumn{2}{|l|}{$100 \%$} \\
\hline & Tidak & 0 & \multicolumn{2}{|l|}{ - } \\
\hline \multirow{2}{*}{$\begin{array}{l}\text { Membersihkan peralatan } \\
\text { memerah susu/ } \\
\text { penampung susu }\end{array}$} & Ya & 14 & \multicolumn{2}{|l|}{$100 \%$} \\
\hline & Tidak & 0 & \multicolumn{2}{|l|}{ - } \\
\hline \multirow{3}{*}{$\begin{array}{l}\text { Memanaskan susu } \\
\text { setelah diperah }\end{array}$} & Ya & 3 & \multicolumn{2}{|l|}{$21 \%$} \\
\hline & $\begin{array}{l}\text { Kadang- } \\
\text { kadang }\end{array}$ & 4 & \multicolumn{2}{|l|}{$29 \%$} \\
\hline & Tidak & 7 & \multicolumn{2}{|l|}{$50 \%$} \\
\hline \multirow{4}{*}{$\begin{array}{l}\text { Membersihkan kandang } \\
\text { dari kotoran hewan }\end{array}$} & Setiap hari & & 5 & $36 \%$ \\
\hline & \multicolumn{2}{|c|}{ Setiap beberapa hari } & 5 & $36 \%$ \\
\hline & \multicolumn{2}{|c|}{ Setiap beberapa bulan } & 3 & $21 \%$ \\
\hline & \multicolumn{2}{|c|}{ Tidak pernah } & 1 & $7 \%$ \\
\hline
\end{tabular}

Dari tabel 2 dapat disimpulkan peternak sudah melakukan upaya menjaga higienitas saat memerah susu dan menampung susu perah. Akan tetapi upaya menjaga higienitas kandang masih perlu ditingkatkan, hal ini dapat dilihat dari tabel 2 bahwa hanya 36\% peternak yang membersihkan kandang kambing perah dari kotorannya setiap hari, sedangkan kebersihan kandang sangat berpengaruh terhadap risiko kontaminasi susu oleh mikroba patogen (Permatasari, 2018). Risiko penularan mikroba patogen juga akan meningkat apabila tidak dilakukan proses sterilisasi atau pasteurisasi susu hasil perah sebelum dijual untuk dikonsumsi oleh masyarakat, karena susu merupakan salah satu media yang baik untuk pertumbuhan mikroba patogen. Hal ini perlu menjadi perhatian untuk dilakukan edukasi lebih lanjut kepada peternak dan masyarakat, terlebih lagi masih banyak masyarakat yang suka mengonsumsi susu mentah.

Dalam kegiatan PKM ini, terdapat keterbatasan karena tidak dilakukan penilaian secara menyeluruh mengenai aspek pengetahuan, sikap dan perilaku peternak dalam menangani susu perah. Selain itu, kegiatan penyuluhan dan pengisian kuesioner berjalan di satu waktu. Untuk kegiatan PKM selanjutnya dapat dilakukan penilaian aspek pengetahuan, sikap, dan perilaku dengan kuesioner tervalidasi sebelum dilakukan penyuluhan kepada peternak dan masyarakat, sehingga materi yang diberikan dapat lebih tepat sasaran dan sesuai kebutuhan peserta penyuluhan. Selain itu, kegiatan PKM juga dapat dilakukan dalam bentuk pelatihan khusus kepada peternak kambing perah di Desa Cimalaka, Kabupaten Sumedang untuk meningkatkan pengetahuan dan praktik manajemen perawatan kambing perah serta teknik memerah dan penanganan susu agar layak untuk dikonsumsi. 


\section{Analisis Mikrobiologi Susu Kambing Mentah}

Susu kambing seperti susu segar lainnya, dapat dengan mudah terkontaminasi dan rusak oleh bakteri. Hal ini dapat terjadi karena kondisi tidak higienis yang dapat terjadi pada proses pemerahan, penyimpanan serta proses pengiriman susu yang tidak tepat (Suguna, 2012). Kandungan susu yang kaya nutrisi sangat mendukung untuk tumbuhnya mikroba patogen yang dapat membahayakan kesehatan konsumen dan merusak kandungan nutrisi pada susu. Berdasarkan hasil perhitungan angka lempeng total (ALT), keenam sampel susu masih memenuhi standar SNI untuk susu segar yaitu kurang dari $5 \times 10^{4}$ koloni/ml dengan rerata 108,3 koloni/ml.

Berdasarkanidentifikasi bakteriStaphylococcus koagulase positif, ditemukan dua sampel yang tercemar bakteri tersebut. Sementara, tidak ditemukan cemaran bakteri koliform pada seluruh sampel susu. (Tabel 2) Adanya temuan Staphylococcus koagulase positif ini menjadi perhatian bagi pemerah maupun konsumen. Teknik pemerahan yang kurang higienis menyebabkan kontaminasi pada susu yang diperah serta dapat meningkatkan risiko penularan bakteri tersebut kepada kambing yang sehat. Adanya bakteri Staphylococcus koagulase positif ini juga berkaitan erat dengan kondisi ambing yang mengalami inflamasi atau infeksi (Taufik, 2011). Selain itu, salah satu bakteri yang termasuk dalam Staphylococcus koagulase positif adalah Staphylococcus aureus, bakteri ini sering menyebabkan infeksi pada ambing (mastitis) dan juga dapat menyebabkan keracunan makanan dari enterotoksin yang dihasilkan bakteri tersebut (Vasileiou, 2019; Merz, 2016). Pemerah juga berisiko terhadap infeksi zoonosis karena $S$. aureus karena bakteri tersebut merupakan patogen yang dapat menimbulkan berbagai macam infeksi mulai dari infeksi kulit dan jaringan lunak hingga infeksi katup jantung (endokarditis) dan infeksi tulang (osteomielitis) (Rainard, 2018). Temuan ini dapat memberi gambaran kepada peternak maupun pemerah akan pentingnya pemeriksaan rutin ambing dan penjagaan kebersihan ambing untuk mencegah infeksi dan penularan saat proses pemerahan. Pada kegiatan kami, terdapat keterbatasan yaitu tidak dilakukan identifikasi lebih lanjut dari bakteri Staphylococcus koagulase positif. Identifikasi hingga tingkatan spesies disertai perhitungan jumlah koloni per $\mathrm{ml}$ susu akan memberikan gambaran yang komprehensif mengenai kualitas susu kambing segar ini. (Tabel 2)

Berdasarkan pertumbuhan bakteri pada agar MacConkey, kami tidak menemukan adanya pertumbuhan bakteri koliform. Akan tetapi, ditemukan dua sampel yang terkontaminasi oleh bakteri batang gram negatif dengan fermentasi laktosa negatif (bakteri enterik non-koliform). Hal ini menjadi keterbatasan dalam penelitian kami, dimana tidak dilakukan identifikasi lebih lanjut pada bakteri batang gram negatif non-koliform tersebut. Berdasarkan penelitian yang dilakukan oleh Suguna, dkk. bakteri enterik non-koliform dapat ditemukan sebagai cemaran susu kambing segar dengan temuan terbanyak bakteri Klebsiella pneumoniae dan Salmonella spp. (Suguna, 2012). Klebsiella pneumonia diketahui sebagai salah satu penyebab infeksi pada ambing (mastitis), khususnya mastitis subklinis, hal ini menjadi catatan bagi peternak untuk lebih mengenali tanda mastitis subklinis dan melakukan pemeriksaan berkala (Artdita, 2018). Salmonella spp juga diketahui sebagai bakteri penyebab infeksi yang diperantarai makanan yang dapat menimbulkan diare, mual dan muntah hingga demam (WHO, 2007).

Tabel 2 Analisis Mikrobiologi Susu Kambing Segar (Mentah)

\begin{tabular}{cccc}
\hline Sampel & $\begin{array}{c}\text { Hitung } \\
\mathbf{A L T}^{*} \mathbf{( c f u} / \\
\mathbf{m l})\end{array}$ & $\begin{array}{c}\text { Identifikasi Presumsi } \\
\text { Staphylococcus } \\
\text { koagulase positif }\end{array}$ & Koliform \\
\hline A & 10 & - & - \\
B & 80 & + & - \\
C & 90 & - & $-* *$ \\
D & 30 & + & - \\
E & 220 & - & - \\
F & 220 & - & $-* *$ \\
\hline Rerata & & \\
hitung & 108,3 & & \\
ALT & & & \\
* Standar Nasional Indonesia (SNI) maksimal ALT bakteri dari susu \\
segar: 5x10 cfu/ml (SNI 7388:2009) \\
** Ditemukan pertumbuhan bakteri batang gram negatif, fermentasi \\
laktosa negatif (bakteri enterik non-koliform)
\end{tabular}

\section{SIMPULAN}

Berdasarkan perhitungan angka lempeng total (ALT), seluruh sampel susu kambing segar yang diperiksa pada kegiatan PKM ini memenuhi syarat SNI 7388:2009. Pertumbuhan bakteri koliform tidak ditemukan pada seluruh sampel susu. Akan tetapi, terdapat perhatian akan potensi cemaran oleh bakteri Staphylococcus koagulase positif dan bakteri enteric non-koliform yang merupakan patogen penting yang sering menimbulkan masalah kesehatan bagi hewan ternak maupun manusia. Hasil survey menggunakan kuesioner pada kegiatan penyuluhan menunjukkan sebagian besar responden dalam kegiatan penyuluhan terbiasa mengonsumsi susu mentah, selain itu perilaku peternak kambing perah dalam menjaga sanitasi kandang dan higienitas susu masih belum baik. Walaupun berdasarkan analisis mikrobiologi seluruh sampel susu segar dari salah satu peternak kambing perah masih memenuhi syarat SNI berdasarkan ALT, akan tetapi masih ditemukan potensi cemaran oleh bakteri yang berpotensi sebagai patogen. 
Peningkatan pengetahuan dan praktik peternak mengenai kesehatan hewan ternak, manajemen sanitasi dan hygiene hewan ternak, serta teknik memerah dan penanganan susu sangat penting untuk menjaga kualitas susu yang agar layak konsumsi. Selain itu, masyarakat juga harus mengetahui pentingnya proses sterilisasi atau pasteurisasi susu kambing sebelum dikonsumsi agar manfaat yang didapat dari susu kambing segar menjadi lebih optimal.

\section{UCAPAN TERIMAKASIH}

Kegiatan penelitian dan pengabdian pada masyarakat ini mendapatkan dana dari hibah Pengabdian Pada Masyarakat Universitas Padjadjaran tahun 2017. Ucapan terima kasih penulis sampaikan kepada Marwa Rahmati Az Zahra, S.Ked. dan M. Ersyad Hamda, dr., MKes. yang telah turut serta dalam kegiatan survey dan proses pengambilan sampel.

\section{DAFTAR PUSTAKA}

Artdita CA, Lestari FB, Fauzi A, Tanzila EPA. 2018. Klebsiella pneumoniae Isolated from Subclinical Mastitis Milk of Etawah Crossbreed Goat. Jurnal Sain Veteriner. 36 (2) 239-246.

Astuti DA, Sudarman A. 2012. Dairy Goats in Indonesia: Potential, Opportunities and Challenges. Proceedings of the 1st Asia Dairy Goat Conference.

Badan Standardisasi Nasional. Standar Nasional Indonesia (SNI) 7388:2009. Batas Maksimum Cemaran Mikroba dalam Pangan. Jakarta.

Haenlein GFW. 2004. Goat Milk in Human Nutrition. Small Rumin Res. 51 (2) 155-163.

Kateete DP, Kimani CN, Katabazi FA, et al. 2010. Identification of Staphylococcus aureus: DNase and Mannitol salt agar improve the efficiency of the tube coagulase test. Ann. Clin. Microb. 9 (23).

Merz A, Stephan R, Johler S. 2016. Staphylococcus aureus Isolates from Goat and Sheep Milk Seem to Be Closely Related and Differ from Isolates Detected from Bovine Milk. Front. Microbiol.7 (319).

Nurliyani, Suranindyah Y, Pretiwi P. 2015. Quality and Emulsion Stability of Milk from Ettawah Crossed Bred Goat During Frozen Storage. Procedia Food Sci. 3 142-149.

Permatasari RI. 2018. Higiene, Sanitasi dan Kualitas Bakteriologis Susu Sapi di Dusun Krajan, Desa Gendro, Kecamatan Tutur, Kabupaten Pasuruan. Jurnal Kesehatan Lingkungan. 10 (4) 343-350.

Rainard P, Foucras G, Fitzgerald JR, Watts JL, Koop G, Middleton JR. 2018. Knowledge gaps and research priorities in Staphylococcus aureus mastitis control. Transbound Emerg Dis. 65 (Suppl. 1) 149-165.

Suguna, M., Rajeev Bhat, Wan Nadiah, W.A. 2012. Microbiological quality evaluation of goat milk collected from small scale dairy farms in Penang Island, Malaysia. Int. Food Res. J. 19 (3) $1241-1245$

Taufik E, Hildebrandt G, Kleer JN, et al. 2011. Microbiological Quality of Raw Goat Milk in Bogor, Indonesia. Media Peternak. 34 (2) $105-111$

Vasileiou NGC, Chatzopoulos DC, Sarrou S, et al. 2019. Role of Staphylococci in Mastitis in Sheep. J. Dairy Res. 86 254-266.

World Health Organization (WHO). Foodborne Disease Outbreaks: Guidelines for Investigation and Control. 2007. (https:// www.who.int/foodsafety/publications/ foodborne_disease/Section_6.pdf, diakses 4 Desember 2019) 